\title{
Early routine amniotomy: an unnecessary procedure
}

\author{
*Ndayisenga, J.P. ${ }^{1,2,3}$, Mukamana, D. ${ }^{1}$, Tengera O. ${ }^{1,3}$, Murekezi, J. ${ }^{3,4}$, Muhayimana, A. ${ }^{1,3}$, \\ Nsaba Uwera, Y.D.. ${ }^{1,3}$
}

\begin{abstract}
Early routine amniotomy, also known as artificial rupture of the amniotic membrane, is one of the procedures used to induce and accelerate labour before cervical dilation reaches four centimeters. Because of its benefits and risks, there are at least two schools of thought about this controversial issue. The purpose of this paper is to argue against early routine amniotomy as an unnecessary procedure that can have drastic and unintended outcomes associated with the labour process, the fetus, and the mother. This commentary paper articulates that early routine amniotomy is a questionable procedure because its risks outweigh its benefits. Therefore, routine early amniotomy should be discouraged among obstetrical procedures.
\end{abstract}

Keywords: Amniotomy, artificial rupture of membrane, routine, labour, process

*Corresponding author

Jean Pierre, $\mathbf{N}$.

ORCID -ID: http://orcid.org/0000-0002-3508-975X

Email:ndayijepi45@gmail.com

\footnotetext{
${ }^{1}$ School of Nursing and Midwifery, University of Rwanda, Kigali, Rwanda

${ }^{2}$ Arthur Labatt Family School of Nursing, Western University, London, Canada

${ }^{3}$ Rwanda Association of Midwives, Kigali, Rwanda

${ }^{4}$ King Faisal Hospital, Kigali, Rwanda
} 


\title{
Amniotomie de routine précoce: Une procédure a découragé
}

\author{
*Ndayisenga, J.P. ${ }^{1,2,3}$, Mukamana, D. ${ }^{1}$, Tengera O. ${ }^{1,3}$, Murekezi, J. ${ }^{3,4}$, Muhayimana, A. ${ }^{1,3}$, \\ Nsaba Uwera, Y.D. ${ }^{1,3}$
}

\section{Résumé}

L'amniotomie de routine précoce, également connue sous le nom de rupture artificielle de la membrane amniotique, est l'une des procédures utilisées pour induire et accélérer le travail avant que la dilatation cervicale n'atteigne quatre centimètres. En raison de ses avantages et de ses risques, il existe au moins deux écoles de pensée sur cette question controversée. Le but de cet article est de plaider contre l'amniotomie de routine précoce en tant que procédure inutile qui peut avoir des conséquences drastiques et imprévues associées au processus de travail, au foetus et à la mère. Cet article de commentaire indique que l'amniotomie de routine précoce est une procédure discutable car ses risques l'emportent sur ses avantages. Par conséquent, l'amniotomie précoce de routine doit être découragée parmi les procédures obstétricales.

Mots-clés: Amniotomie, rupture artificielle de membrane, routine, travail, processus

*Corresponding author

Ndayisenga, J.P.

ORCID -ID: http://orcid.org/0000-0002-3508-975X

Email:ndayijepi45@gmail.com

\footnotetext{
${ }^{1}$ School of Nursing and Midwifery, University of Rwanda, Kigali, Rwanda

${ }^{2}$ Arthur Labatt Family School of Nursing, Western University, London, Canada

${ }^{3}$ Rwanda Association of Midwives, Kigali, Rwanda

${ }^{4}$ King Faisal Hospital, Kigali, Rwanda
} 


\section{INTRODUCTION}

Early routine amniotomy, also known as artificial rupture of the amniotic membrane, is one of the procedures used to induce and accelerate labour. According to Cooney and Bastek (1), early amniotomy occurs when it is performed before cervical dilation reaches $4 \mathrm{~cm}$. This procedure is becoming the most common routine midwifery and obstetrical practice in lowto-middle-income countries (2). Nurses, midwives, and obstetricians perform early amniotomy in order to initiate and accelerate labour(3).

Because of its benefits and risks, there are at least two schools of thought about this controversial issue. For instance, some maternity care providers believe that an early routine amniotomy should be avoided as it can cause unintended outcomes for the woman and the fetus such as cord prolapse, increased fetal heart abnormalities, fetal distress increases the rate of cesarean section, maternal and neonatal infection (2-5). On the other hand, other maternity care providers believe that an early routine amniotomy should be introduced as part of standard labour management and care in maternity as it is associated with some benefits like a shortened length of labour (6-8). The purpose of this paper is to argue against early routine amniotomy as an unnecessary procedure that can have drastic and unintended outcomes associated with the labour process, the fetus, and the mother.

Accelerating labour with early amniotomy is associated with unintended outcomes in labour process.

According to World Health Organization (WHO) (4), acceleration of labour is the process of stimulating the uterus done by obstetricians, or nurse and midwives to increase the duration, intensity, and frequency of contractions after the onset of spontaneous labour. Some studies support that early routine amniotomy may shorten labour duration by releasing local prostaglandins and oxytocin, resulting in uterine contractions and quicker cervical dilation $(6,9,10)$. Yet, the effect of amniotomy on the duration of labour is reported in a Cochrane Review as still a controversial issue, concluding that amniotomy does not produce any statistical difference in the length of the first stage of labour (3).

However, proponents argue that early amniotomy increases chances for spontaneous birth without using drugs or other techniques to accelerate labour (11). Although such claims exist, research shows that early routine amniotomy increases the rate of caesarian delivery for presumed fetal distress (12). WHO has recommended that early amniotomy is a practice to be avoided because it is not beneficial for the treatment of prolonged labour (9). Thus, we strongly support the position that early routine amniotomy should be discouraged because it was not proven to shorten the duration of labour $(4,5,12)$. Early routine amniotomy is not only associated with unintended poor labour progress, but also increases risks to the fetus and newborn during and after labour.

Early routine amniotomy can lead to poor fetal and neonatal outcomes during labour and after delivery.

Early routine amniotomy may reduce the duration of labour but there is no clear evidence that a shorter labour is beneficial to the fetus (5). Studies show that early routine amniotomy increases the frequency of neonatal infection, and if placental blood vessels are punctured results in fetal blood loss, and cord prolapse $(3,5,13)$. In four case-controlled studies reported between 1985-2006 it was concluded that amniotomy does not cause cord prolapse and it was proposed that early amniotomy could prevent the same (1416). In another study, early amniotomy was attributed to a reduction in amniotic fluid quantity and a leading cause of increased cord compression $(12,17)$ with evidence of a $10 \%$ rate of cord prolapses (5). The same author reported a causal relationship between amniotomy, and cord prolapse sometimes resulting in fetal and neonatal death suggesting the anti-bacterial benefit of amniotic fluids that may play an important role in protecting the fetus against infection (5).

Even though it is known that amniotomy is associated with increased risk of neonatal infections, including perinatal HIV transmission, Cooney and Bastek (1) believe that early routine amniotomy does not increase incidence of chorioamnionitis, while others have reported evidence of newborn infection associated with long intervals between ruptured membranes and delivery $(18,19)$. Instead it has been reported of a decreased occurrence of neonatal infection with normal deliveries without amniotomy $(5,18)$. Hence, subjecting women in labour to amniotomy could predispose them to an increased risk of maternal morbidity. Borders reported that if a woman in labour shows no evidence of any fetal distress or any other complication, the routine amniotomy should not 
be done to enable the maternal fetal monitoring in normal progress of labour. To reduce risks and neonatal morbidity amniotomy needs to be discouraged.

Early routine amniotomy can lead to unintended poor labour outcomes for the mother.

Though, amniotomy procedure can assist in assessing the status of amniotic fluid during labour, nonetheless, Cohain (5), stated that surveillance for meconium using amniotomy may result in unnecessary interventions like cesarean sections. The effect of early amniotomy on cesarean section delivery is still a controversial issue (13). According to Ghafarzadeh et al (13), early amniotomy is associated with low rates of cesarean delivery as well as dystocia. Different studies have shown that early amniotomy is associated with increased risk for cesarean deliveries $(2,5,20)$. In addition, amniotomy increases the rate of cesarean section because of meconium detection as a result of early amniotomies (20). Women exposed to cesarean sections as a result of early routine amniotomy are also at risk of developing complications related to the cesarean procedure such as anesthetic complications, severe hemorrhage, infection and death related to surgery (7). In addition, the literature argues that amniotomy can be associated with adverse psychological effects. To reduce maternal morbidity related to amniotomy, it is better to avoid early routine amniotomy.

\section{CONCLUSION}

During labour, nurses, midwives, and obstetricians' intention is to promote the normal progression of labour and achieve the best labour and delivery outcomes for both the mother and the baby. One way to achieve this is to avoid unnecessary and harmful procedures like early routine amniotomy. Studies show that early routine amniotomy is a questionable procedure because its risks outweigh its benefits. The removal of early amniotomy from the standards of labour management, will contribute significantly to the reduction of maternal and neonatal morbidities. Nursing and midwifery implication are clear and very necessary to discourage and avoid unnecessary routine amniotomy in both pre-service and in-service nursing and midwifery education and practices. When caring for mothers in labour, nurses, midwives, and obstetricians have to play a significant role by providing all information and evidence about the risks related to early amniotomy to all mothers in labour. This evidence can be used as the foundation by which to enhance the involvement of women in decision making before starting to perform amniotomies.

Limitation: This paper is based on authors' arguments and is supported by existing scientific literature. There were limited local works on the risks and benefits of routine artificial rupture of fetal membranes; therefore, to promote evidencebased practice, more research on benefits and risks in this area are still needed.

Acknowledgment: We acknowledge contributions from authors. We acknowledge the University of Rwanda, the School of Nursing and Midwifery for allocating writing time to this scholarly activity.

Funding: No funding was obtained in writing this paper.

Conflict of interests: None is declared.

\section{REFERENCES}

1. Cooney LG, Bastek JA. The Association between Early Artificial Amniotomy and Chorioamnionitis in Nulliparous Induction of Labor. Int Sch Res Not [Internet]. 2014;2014:1-8. Available from: http://www.ncbi.nlm.nih.gov/pubmed/27379338 \%5Cnhttp://www.pubmedcentral.nih.gov/articler ender.fcgi?artid=PMC4897382

2. Malarvizhi V, Swati R, Santosh j B, Abraham A, Antonisamy B. Randomized controlled trial of the effect of amniotomy on the duration of spontaneous labor. Int $\mathrm{J}$ Gynecol Obstet [Internet]. 2017;138(2):152-7. Available from: http://doi.wiley.com/10.1002/ijgo.12203

3. Smyth R, Markham C, T D. Amniotomy for shortening spontaneous labour. Cochrane Database Syst Rev [Internet]. 2013;4(6):1-87. Available from: www.cochranelibrary.com

4. WHO. Recommendations for Augmentation of Labour Summary Recommendations Grouped by Process of Care. 2015 Apr;(April):1-4. Available f $\quad \mathrm{r} \quad \mathrm{o} \quad \mathrm{m}$ http://apps.who.int/iris/bitstream/10665/174001/ 1/WHO RHR 15.05 eng.pdf?ua $=1$

5. Cohain JS. The less studied effects of Amniotomy. J Matern Neonatal Med [Internet]. 2013;26(17):1687-90. Available from: http://www.tandfonline.com/doi/full/10.3109/14 767058.2013.798286

6. Vadivelu M, Rathore S, Benjamin SJ, Abraham A, Belavendra A, Mathews JE. Randomized controlled trial of the effect of amniotomy on the duration of spontaneous labor. Int $\mathrm{J}$ Gynecol Obstet [Internet]. 2017;138(2):152-7. Available 
from: http://doi.wiley.com/10.1002/ijgo.12203

7. Lavender T, Hofmeyr GJ, Neilson JP, Kingdon C, Ml G. Europe PMC Funders Group Caesarean section for non-medical reasons at term. Cochrane Database Syst Rev. 2014;3(February 2012):1-22.

8. Smyth R, Markham C, Dowswell T. Amniotomy for shortening spontaneous labour. Cochrane Database Syst Rev. 2013;4(6):1-87.

9. WHO. Recommendations for Augmentation of Labour. Highlights and Key Messages from World Health Organization's 2014 Global Recommendations. 2015;1-4. Available from: www.mcsprogram.org

10. Neilson JP, Lavender T, Quenby S, Wray S. Obstructed labour. Br Med Bull. 2003;67(October):191-204.

11. Gross.M M, Fromke C, Hecher.Hartmut. The timing of amniotomy, oxytocin and neuraxial analgesia and its association with labour duration and mode of birth. Arch Gynecol Obstet [Internet]. 2014;289(1):41-8. Available from: https://link.springer.com/content/pdf/10.1007\%2 Fs00404-013-2916-7.pdf

12. Ruamsap K, Panichkul P. The effect of early versus late amniotomy on the course of labor. J Med Assoc Thail [Internet]. 2017;100(2):125-32. A v a i 1 a b l e f $\mathrm{r}$ o $\mathrm{m}$ : https://www.scopus.com/inward/record.uri?eid= 2 - $\quad \mathrm{s} \quad 2 \quad$. 00 $85018709149 \&$ partnerID $=40 \&$ md $5=802188320$ 95029469bbae4c74f94b7cf

13. Ghafarzadeh $M$, Moeininasab S, Namdari $M$. Effect of early amniotomy on dystocia risk and cesarean delivery in nulliparous women: a randomized clinical trial. Arch Gynecol Obstet [Internet]. 2015;292(2):321-5. Available from: http://dx.doi.org/10.1007/s00404-015-3645-x

14. Ylä-Outinen, A., Heinonen, P.K., Tuimala R. Predisposing and risk factors of umbilical cord prolapse. Acta Obstet Gynecol Scand [Internet]. 1985;64(7):567-70. Available from: http://www.embase.com/search/results?subactio $\mathrm{n}=$ viewrecord $\&$ from $=$ export\&id $=\mathrm{L} 16113558 \% 5$ Cnhttp://sfx.library.uu.nl/utrecht?sid=EMBASE $\&$ issn $=00016349 \&$ id $=$ doi:\&atitle=Predisposing
+ and + risk + factors + of + umbilical + cord + prolapse $\&$ stitle $=$ ACTA + OBSTET. + GYNECOL.+ SCAN D.\&tit

15. Dilbaz B, Ozturkoglu E, Dilbaz S, Ozturk N, Sivaslioglu AA, Haberal A. Risk factors and perinatal outcomes associated with umbilical cord prolapse. Arch Gynecol Obstet. 2006;274(2):104-7.

16. Uygur.D, Kis.S, Tuncer.R, Ozcan.F.S, Erkaya.S. Risk factors and perinatal outcomes associated with umbilical cord prolapse. Int J Arch Gynecol Obstet [Internet]. 2002;78(2):127-30. Available f $\quad r \quad$ o $\quad$ m : http://www.embase.com/search/results?subactio $\mathrm{n}=$ viewrecord\&from $=$ export\&id $=\mathrm{L} 43601908 \% 5$ Cnhttp://dx.doi.org/10.1007/s00404-006-0142-2

17. Brisson-Carroll G, Fraser W, Breart G KI, Thornton J. the effect of routine early amniotomy on spontaneous labor: A meta-analysis. 1996;87(5):891-6.

18. Seaward PG, Hannah ME, Myhr TL, Farine D, Ohlsson A, Wang EE, et al. International multicenter term PROM study: evaluation of predictors of neonatal infection in infants born to patients with premature rupture of membranes at term. Premature Rupture of the Membranes. Am J Obs Gynecol [Internet]. 1998;179(3 Pt 1):635-9. A v a i l a b l e f $\mathrm{r}$ o m : http://www.ncbi.nlm.nih.gov/entrez/query.fcgi?c $\mathrm{md}=$ Retrieve $\& \mathrm{db}=$ PubMed $\& \mathrm{dopt}=$ Citation $\&$ list uids $=9757963$

19. Heath PT, Balfour GF, Tighe H, Verlander NQ, Lamagni TL, Efstratiou A. Group B streptococcal disease in infants: a case control study. Arch Dis Child [Internet]. 2009;94(9):674-80. Available f $r$ o $\quad$ m : http://adc.bmj.com/cgi/doi/10.1136/adc.2008.14 8874

20. Bala A, Bagga R, Kalra J, Dutta S. Early versus delayed amniotomy during labor induction with oxytocin in women with Bishop's score of $\geq 6$ : a randomized trial. J Matern Neonatal Med [Internet]. 2017;0(0):1-8. Available from: https://doi.org/10.1080/14767058.2017.1362381

How to cite this article:

Ndayisenga, J.P., Donatilla, M., Tengera Olive, T., Josephine, M., Alice, M., Delphine, N.U.Y. Early routine amniotomy: an unnecessary procedure. Research Journal of Health Science, 2021, 9(1): 77-81 